\title{
Comparison of the outcomes of isolated anterior cruciate ligament reconstruction and combined anterolateral ligament suture tape augmentation and anterior cruciate ligament reconstruction
}

\author{
Tunay Erden, $M^{1}{ }^{(\mathbb{D}}$, Berkin Toker, $\mathrm{MD}^{1}{ }^{\mathbb{D}}$, Ali Toprak, $\mathrm{MD}^{2}{ }^{\mathbb{D}}$, Ömer Taşer, $\mathrm{MD}^{1}{ }^{1}$ \\ 'Department of Orthopedics and Traumatology, Acıbadem Fulya Hospital Sports Medicine Center, Istanbul, Turkey \\ ${ }^{2}$ Department of Biostatistics and Medical Informatics, Faculty of Medicine, Bezmialem Vakıf University, Istanbul, Turkey
}

\begin{abstract}
Anterior cruciate ligament (ACL) tears are common sports-related injuries. ${ }^{[1,2]}$ Several surgical techniques for ACL reconstruction have been developed to improve the functional stability of the injured knee and minimize articular cartilage and meniscal damage as well as provide athletes a chance to return to their preinjury level of sporting activities. ${ }^{[3-5]}$ Although the long-term outcomes of ACL reconstruction are favorable, normal rotational stability of the knee is not fully restored, and such abnormal biomechanics of the joint can cause additional articular injuries. ${ }^{[6-11]}$
\end{abstract}

Reconstruction or augmentation of the anterolateral ligament (ALL) has been proposed to reduce rotatory knee instability in conjunction

Received: August 06, 2020

Accepted: October 12, 2020

Published online: January 06, 2021

Correspondence: Tunay Erden, MD. Acıbadem Fulya Hastanesi Spor Hekimliği Merkezi, Ortopedi ve Travmatoloji Bölümü,

34349 Beşiktaș, İstanbul, Türkiye.

E-mail: doktorerden@hotmail.com

Doi: $10.5606 /$ ehc. 2020.78201

Citation: Erden T, Toker B, Toprak A, Tașer Ö. Comparison of the outcomes of isolated anterior cruciate ligament reconstruction and combined anterolateral ligament suture tape augmentation and anterior cruciate ligament reconstruction. Jt Dis Relat Surg 2021:32(1):129-136

(C2021 All right reserved by the Turkish Joint Diseases Foundation

This is an open access article under the terms of the Creative Commons Attribution-NonCommercial License, which permits use, distribution and reproduction in any medium, provided the original work is properly cited and is not used for commercial purposes (http://creativecommons.org/licenses/by-nc/4.0/).

\section{ABSTRACT}

Objectives: This study aims to compare the outcomes of isolated anterior cruciate ligament (ACL) reconstruction and combined anterolateral ligament (ALL) suture tape augmentation (STA) and ACL reconstruction after a minimum follow-up of two years.

Patients and methods: This retrospective study included 63 patients (36 males, 27 females; mean age 27.8 \pm 4.0 ; range, 19 to 35 years) who had unilateral ACL injury and participated in pivoting sports and were randomly assigned to undergo either isolated ACL reconstruction (Group 1, n=33) or combined ACL reconstruction and ALL STA (Group 2, n=30) between January 2015 and February 2018. The presence of an associated meniscal injury, chondral pathology, contralateral ACL rupture, and residual pivot shift; subjective and objective International Knee Documentation Committee scores; Cincinnati and Lysholm functional scores; KT-1000 measurements; and graft rupture rate were evaluated.

Results: Patients were followed for a minimum of two years. The groups did not differ with respect to age, sex, side, time from injury to surgery, postoperative follow-up time, ACL graft size, contralateral ACL rupture, graft size, partial meniscectomy, chondral pathology or preoperative physical examination results. A total of $9.1 \%$ of the patients in Group 1 and $0 \%$ of those in Group 2 presented postoperative positive pivot shift $(p=0.357)$. The graft failure rate was $6.06 \%(n=2)$ in Group 1 and $0 \%$ in Group $2(\mathrm{p}=0.270)$. In the final evaluation, compared with Group 1, Group 2 showed better anteroposterior clinical stability, as evaluated by KT-1000 arthrometry $(\mathrm{p}=0.006)$. Although better results were observed in Group 2, the clinical evaluation results for postoperative function did not differ significantly between groups.

Conclusion: Combined ALL STA and ACL reconstruction was found to be effective in improving subjective and objective outcomes. Nevertheless, these findings were not significantly superior to those of isolated ACL reconstruction with hamstring grafts, except for the side-to-side differential anterior laxity testing results.

Keywords: Anterior cruciate ligament reconstruction, anterolateral ligament, augmentation, knee, ligament augmentation, suture tape. 
with ACL reconstruction. ${ }^{[12-14]}$ Several indications have been described for combined ACL and ALL reconstruction, such as a chronic ACL lesion, participation in pivoting sports or in sports at a high level, knee recurvatum, the presence of a Grade 3 pivot shift, an associated Segond fracture, or a lateral femoral notch sign on radiographs. ${ }^{[15,16]}$

Anterolateral ligament augmentation with the suture tape technique is a simple, minimally invasive, and quick procedure that provides additional anterolateral rotational stability and reinforces the ligament for secondary stabilization, supporting early mobilization and encouraging natural healing of the ligament by protecting it during the healing phase; in addition, it is usually recommended to be performed together with ACL reconstruction. ${ }^{[13,17]}$ In this study, we aimed to compare the outcomes of isolated ACL reconstruction and combined ALL suture tape augmentation (STA) and ACL reconstruction after a minimum follow-up of two years.

\section{PATIENTS AND METHODS}

In this study, medical records of 160 patients who underwent unilateral primary ACL reconstruction by a senior surgeon with 25 years of experience between January 2015 and February 2018 were retrospectively analyzed. Patients who met at least one of the following criteria were indicated for isolated ACL reconstruction or combined ALL STA and ACL reconstruction: Grade 2 or 3 pivot shift $(\mathrm{n}=28)$, a high level of sporting activity $(\mathrm{n}=23)$, participation in pivoting sports $(\mathrm{n}=30)$, a chronic ACL injury $(n=14)$, or a Segond fracture $(n=1)$. The study protocol was approved by the Acrbadem University Ethics Committee (Institutional Review Board no: 2020-06/23). A written informed consent was obtained from each patient. The study was conducted in accordance with the principles of the Declaration of Helsinki. The inclusion criteria were patients older than 18 years who presented to the senior author with an acute or chronic ACL rupture, underwent primary single-bundle ACL reconstruction with a hamstring graft, combined ALL STA and ACL reconstruction, had an isolated ACL injury without a concomitant ligament injury, normal alignment of the lower extremities, and a minimum follow-up duration of two years. The exclusion criteria were patients who underwent meniscal repair, concomitant subtotal or total meniscectomy (exceptsmall meniscectomies less than $50 \%$ of the meniscus width), had multiligamentous knee injuries, previous contralateral ACL injury, generalized joint hypermobility, chondral lesions with an Outerbridge Grade of 3 or 4 during arthroscopy, previous ipsilateral or contralateral knee surgery, were treated with allografts or lived a long distance away, making routine follow-up challenging. Finally, a total of 63 patients ( 36 males, 27 females; mean age 27.8 \pm 4.0 ; range, 19 to 35 years) were included. Patients were distributed into two groups according to their first day of arrival in the hospital. Patients arriving on Monday, Tuesday and Wednesday were added to Group 1, while those arriving on Thursday, Friday and Saturday were added to Group 2. According to the criteria listed above, all patients were classified into two groups: Group 1, which consisted of patients who underwent isolated ACL reconstruction with a hamstring graft $(n=33)$ and Group 2, which consisted of patients who underwent ACL reconstruction with a hamstring graft and ALL STA $(n=30)$.

All operations were performed by a single experienced senior surgeon. Semitendinosus and gracilis tendon grafts (quadrupled) were used for single-bundle all-inside ACL reconstruction. After the entry point of the femoral canal was localized, a femoral canal was created using the appropriate femoral guide and a FlipCutter ${ }^{\circledR}$ (Arthrex, Naples, FL, USA). The tibial footprint was located by placing a tibial guide in the center of the ACL footprint, and the tibial canal was then created using the tibial guide and FlipCutter ${ }^{\circledR}$. Finally, the graft was passed through the medial portal to the femoral socket and stabilized with TightRope ${ }^{\circledR}$ (Arthrex, Naples, FL, USA). Then, the tibial end was passed through the tibial canal and stabilized with TightRope ${ }^{\circledR}$.

Anterolateral ligament STA was performed in the same session after ACL reconstruction was completed. The surgical technique we used has recently been described by different authors, with minor differences. ${ }^{[12,13]}$ The anterior margin of the fibular head, lateral femoral epicondyle, Gerdy tubercle, and the distal joint line were palpated and marked (Figure 1a). ${ }^{[12,13]}$ The tibial insertion was marked halfway between the Gerdy tubercle and the anterior margin of the fibular head, $10 \mathrm{~mm}$ below the joint line. ${ }^{[13]}$

An ultrahigh-strength $2 \mathrm{~mm}$ wide tape (FiberTape ${ }^{\circledR}$, Arthrex, Naples, FL, USA) and two anchors (SwiveLock ${ }^{\circledR}$, Arthrex, Naples, FL, USA) were used for STA. A 1 to $2 \mathrm{~cm}$ vertical incision was performed starting over the lateral femoral epicondyle in the posterior and proximal directions. After the soft tissue was dissected, the iliotibial band was split, and it was ensured that there was no contact with the ACL femoral tunnel. The 
first $2.4 \mathrm{~mm}$ Kirschner wire (K-wire) was placed at the anatomic femoral insertion of the ALL, just proximal and posterior to the lateral femoral epicondyle (Figure 1b). Then, the skin was incised horizontally at the previously marked point for ALL tibial insertion, and the second $2.4 \mathrm{~mm}$ K-wire was placed at the anatomic tibial insertion of the ALL (Figure 1b). A hemostat was directed distally under the iliotibial band, superficial to the lateral collateral ligament. The hemostat was distally moved sideways to create a tunnel for the FiberTape ${ }^{\circledast}$ and to break any adhesions (Figure 1b). For measurements of isometric points, a suture was looped around the two K-wires to assess the level of tension during the range of motion (ROM) between $0^{\circ}$ and $90^{\circ}$ of flexion to obtain a bundle that reproduced the ALL biomechanics and was tight in extension and slack in flexion (Figure 2a). ${ }^{[18]}$ The wires were repositioned if the placement was found to be unsatisfactory (major length variation or suture slack in extension). After a hole $20 \mathrm{~mm}$ in depth was predrilled with a $4.5 \mathrm{~mm}$ drill and the hole was tapped, a $4.75 \mathrm{~mm}$ SwiveLock ${ }^{\circledR}$ loaded with a no. 2 FiberTape ${ }^{\circledR}$ was placed in femoral insertion (Figure 2b). The femoral drill hole was kept under direct vision to prevent the SwiveLock ${ }^{\circledR}$ from being placed superficially and the position of the drill hole from being lost. The FiberTape ${ }^{\circledR}$ was moved to the tibial incision using a lead suture transported by the hemostat. Under direct vision of the bony ALL insertion location, the $5.5 \mathrm{~mm}$ SwiveLock ${ }^{\circledast}$ was predrilled and tapped (Figure 2c). The FiberTape ${ }^{\circledR}$ was then assessed during the ROM between $0^{\circ}$ and $90^{\circ}$ of flexion to confirm the absence of overconstraint. Tibial fixation was performed in neutral rotation and near full extension. This position has been shown by Inderhaug et al. ${ }^{[14]}$ to restore knee kinematics.

The same postoperative standardized rehabilitation program was used for both reconstruction techniques, and the program involved brace-free, immediate full weight bearing after the procedure and progressive ROM exercises. The focus of early rehabilitation was to obtain quadriceps muscle activation and full extension. Crutches were used until quadriceps muscle control was established. Routine clinical follow-up examinations were performed at 2, 6, 12 , and 24 weeks and at one year. Patients with no complaints after the first year were routinely called for a clinical follow-up examination once a year. A gradual return to sports activities was allowed

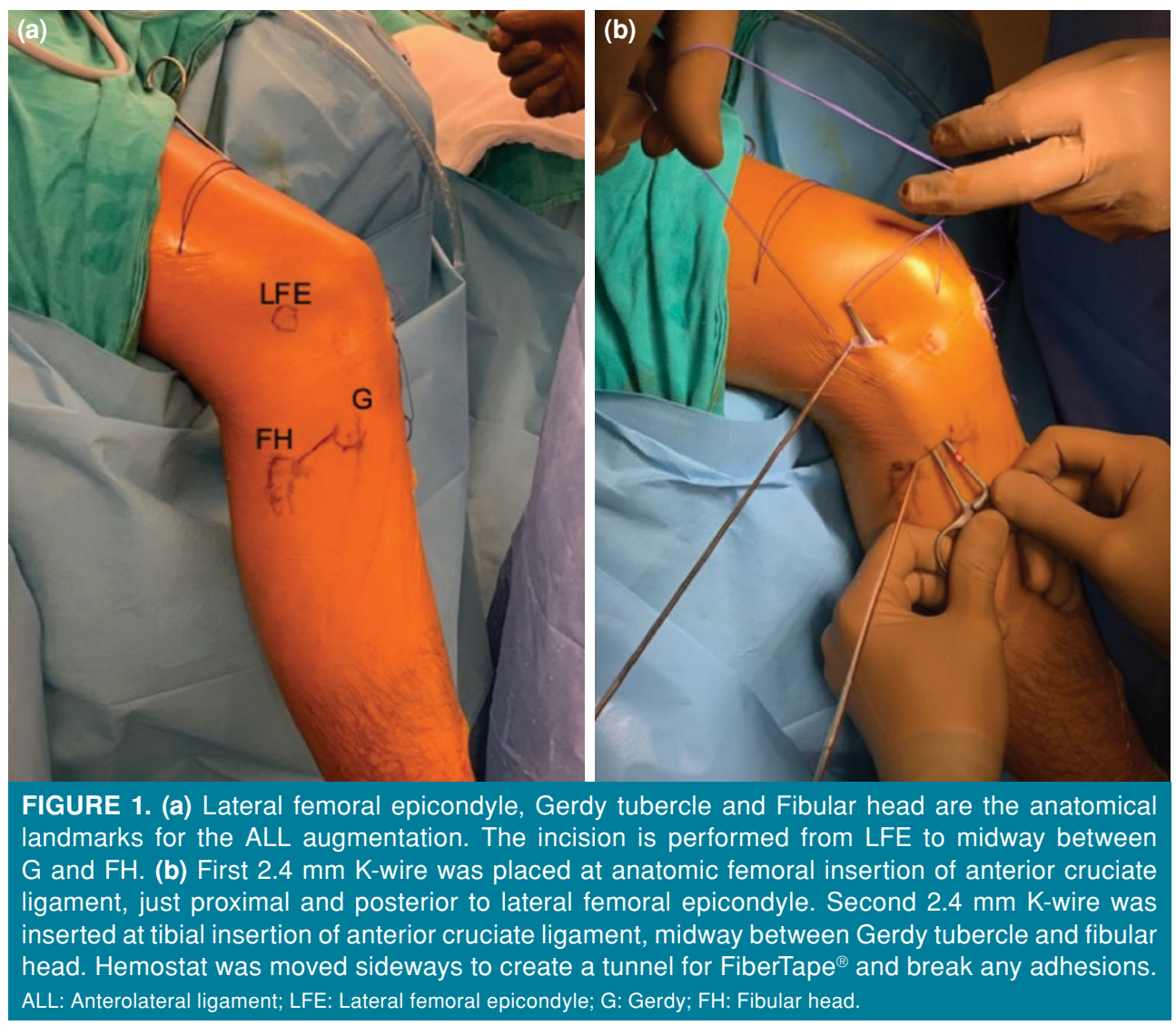



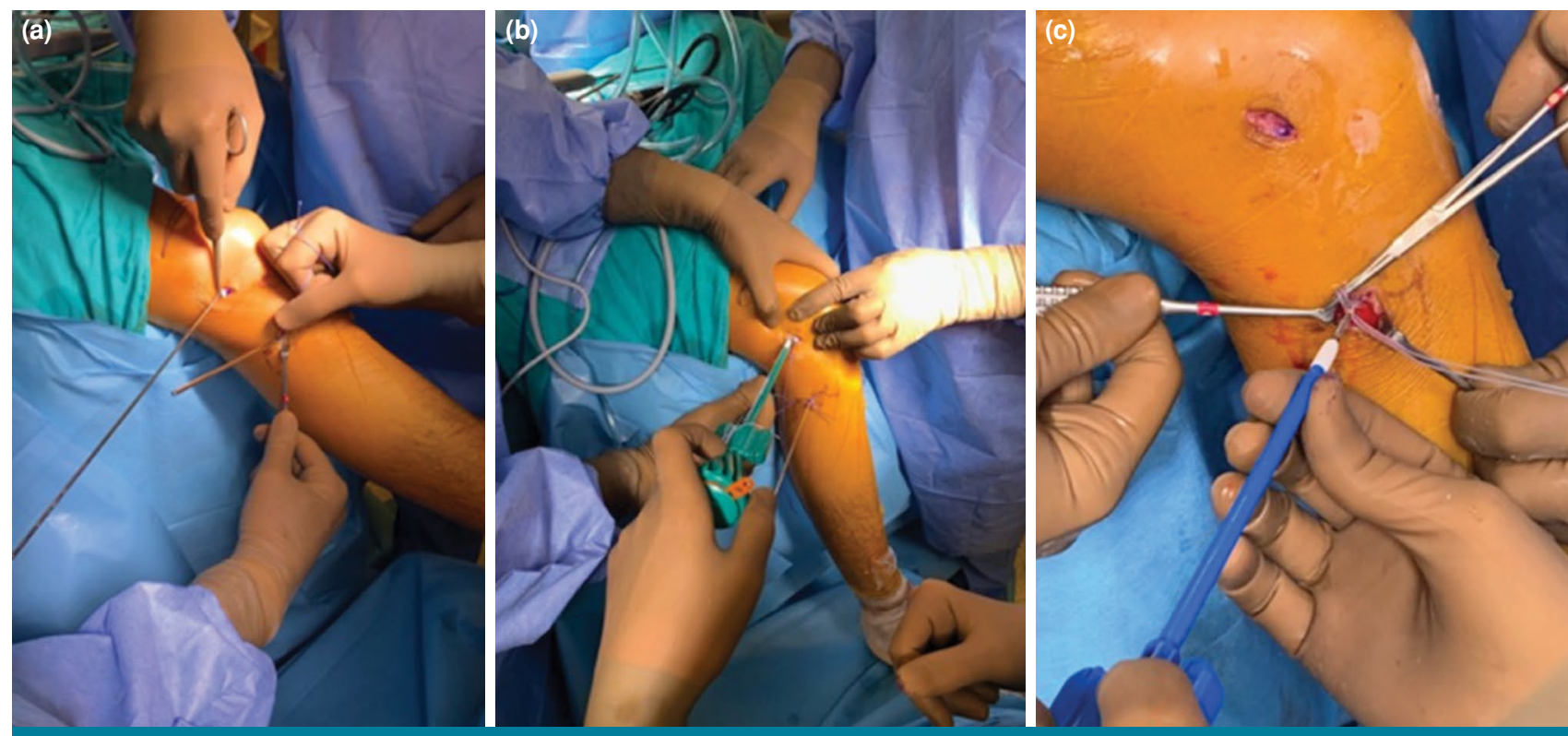

FIGURE 2. (a) For measurements of isometric points, a suture was looped around K-wires to assess tension during range of motion. (b) $4.75 \mathrm{~mm}$ diameter SwiveLock ${ }^{\circledR}$ anchor was fixed on femoral side. (c) $5.5 \mathrm{~mm}$ diameter SwiveLock ${ }^{\circledR}$ anchor was fixed on tibial side.

starting at six months for pivoting noncontact sports and at nine months for pivoting contact sports after the isokinetic test (a deficit of more than $20 \%$ in eccentric or concentric hamstring strength or the presence of any quadriceps deficits led to the return to sports being deferred, and testing was repeated two to three months later).

The demographic data (age, sex, side, duration of injury before surgery, pre- and postoperative follow-up) and additional parameters (duration of injury before surgery, ACL graft size, graft failure rate, chondral lesion, and meniscectomy) of the two groups were compared.

Clinical examinations were conducted preoperatively and at a minimum of 24 months postoperatively. All physical examinations were performed by trained orthopedic fellows blinded to the groups. Knee stability was evaluated using the pivot-shift test and Lachman test. The results of the pivot-shift test had scores of 0 (normal), 1 (subluxation), 2 (jump), or 3 (transient lock), and the Lachman test had scores of $0(<3 \mathrm{~mm})$, 1 ( $\geq 3$ and $<5 \mathrm{~mm}), 2(\geq 5$ and $<10 \mathrm{~mm})$, or $3(\geq 10 \mathrm{~mm})$. A KT-1000 arthrometer (MEDmetric ${ }^{\circledR}$, San Diego, CA, USA) (used to assess the difference between the affected and contralateral knees in millimeters) in $30^{\circ}$ of knee flexion with an applied force of $134 \mathrm{~N}$ was used to evaluate anterior stability. Two different examiners measured anterior stability with the KT-1000 arthrometer to improve reliability, and the average of the measurements from the two examiners was used.

Pre- and postoperative functional evaluations were performed using the International Knee Documentation Committee (IKDC) subjective score, the Cincinnati and the Lysholm knee scoring scale, and the IKDC objective grade.

Graft failure or rerupture was defined as the presence of hypermobility with no clear end point in the Lachman and anterior drawer tests (at least $2+/ 3+$ ) or positive pivot-shift results (at least $2+/ 3+$ ) in the physical examination, as well as instability complaints and the presence of a new graft rupture in magnetic resonance imaging scan. ${ }^{[19]}$ Other complications, such as infection, arthrofibrosis, and ROM loss, were evaluated.

\section{Statistical analysis}

Statistical analysis was performed using the IBM SPSS version 22.0 software (IBM Corp., Armonk, NY, USA). First, a Kolmogorov-Smirnov test was used to determine which variables should be included in the data analysis and whether the data for the variables were normally distributed, but the data were not normally distributed. Therefore, nonparametric tests were used, and the Mann-Whitney U test was used to compare continuous variables across the groups. The chi-square test and Fisher's exact test were used to compare categorical variables between two groups, and the median (first quarter [Q1]-third quarter 


\begin{tabular}{|c|c|c|c|c|c|c|c|}
\hline \multicolumn{8}{|c|}{$\begin{array}{l}\text { TABLE I } \\
\text { acteristics and additional diagno }\end{array}$} \\
\hline \multirow[b]{2}{*}{ Variables } & \multicolumn{3}{|c|}{ Group 1 (Isolated ACL) $(n=33)$} & \multicolumn{3}{|c|}{ Group $2(A C L+A L L ~ S T A)(n=30)$} & \multirow[b]{2}{*}{$p$} \\
\hline & $\mathrm{n}$ & $\%$ & Mean $\pm S D$ & $\mathrm{n}$ & $\%$ & Mean \pm SD & \\
\hline Age (year) & & & $26.1 \pm 4.2$ & & & $27.3 \pm 3.8$ & NS \\
\hline Sex & & & & & & & NS \\
\hline Female & 14 & 4.4 & & 13 & 43.3 & & \\
\hline Male & 19 & 57.6 & & 17 & 56.7 & & \\
\hline Side & & & & & & & NS \\
\hline Right & 14 & 42.4 & & 17 & 56.7 & & \\
\hline Left & 19 & 57.6 & & 13 & 43.3 & & \\
\hline Duration of injury before surgery (month) & & & $4.6 \pm 0.4$ & & & $5.1 \pm 0.7$ & NS \\
\hline Follow-up time (month) & & & $32.7 \pm 5.7$ & & & $31.7 \pm 5.3$ & NS \\
\hline Partial meniscectomy & 5 & 15.2 & & 4 & 13.3 & & NS \\
\hline Chondral pathology (Grade 1 and 2) & 6 & 18.2 & & 5 & 17.7 & & NS \\
\hline Contralateral ACL rupture & 2 & 6.1 & & 1 & 3.3 & & NS \\
\hline Graft size $(\mathrm{mm})$ & & & $8.3 \pm 0.5$ & & & $8.2 \pm 0.5$ & NS \\
\hline Graft rupture & 2 & 6.1 & & 0 & 0 & & NS \\
\hline
\end{tabular}

[Q3]), mean \pm standard deviation, frequency, and percentage constituted the descriptive statistics. The interrater agreement between the two examiners for the Lachman test and pivot-shift test score was evaluated using the Cohen's kappa coefficient. The interobserver reliability of the KT-1000 device was assessed using the intraclass correlation coefficient and the 95\% confidence interval. No sample size estimations were performed because all patients in our hospital database who met the inclusion criteria were included in the analysis, and $p<0.05$ was considered statistically significant.

\section{RESULTS}

The patients were followed for a minimum of two years. The mean follow-up period was $32.7 \pm 5.7$ (range, 25 to 45) months for Group 1 and 31.7 \pm 5.3 (range, 26 to 48) months for Group 2. The groups did

\begin{tabular}{|c|c|c|c|c|c|c|c|c|c|c|c|}
\hline \multicolumn{12}{|c|}{ Comparison of preoperativ } \\
\hline \multirow[b]{2}{*}{ Variables } & \multicolumn{5}{|c|}{ Group 1 (Isolated ACL) $(n=33)$} & \multicolumn{5}{|c|}{ Group $2(A C L+A L L S T A)(n=30)$} & \multirow[b]{2}{*}{$p$} \\
\hline & $\mathrm{n}$ & $\%$ & Mean $\pm S D$ & Median & Q1-Q3 & $\mathrm{n}$ & $\%$ & Mean $\pm S D$ & Median & Q1-Q3 & \\
\hline SSD in anterior translation (mm) & & & $7.4 \pm 1.3$ & & & & & $7.7 \pm 1.2$ & & & NS \\
\hline Lachman test & & & & & & & & & & & NS \\
\hline I & 3 & 9.1 & & & & 1 & 3.3 & & & & \\
\hline II & 21 & 63.6 & & & & 22 & 73.3 & & & & \\
\hline III & 9 & 27.3 & & & & 7 & 23.3 & & & & \\
\hline Pivot-shift test & & & & & & & & & & & NS \\
\hline 1 & 4 & 12.1 & & & & 2 & 6.7 & & & & \\
\hline II & 29 & 87.9 & & & & 22 & 73.3 & & & & \\
\hline III & 0 & 0 & & & & 6 & 20 & & & & \\
\hline Lysholm knee score & & & $71.9 \pm 6.2$ & 76 & $70-78.5$ & & & $72.1 \pm 6.4$ & 73 & $68.7-77$ & NS \\
\hline Cincinnati knee score & & & $54.3 \pm 5.5$ & 54 & $50-59$ & & & $53.7 \pm 5.5$ & 52 & $51-58.5$ & NS \\
\hline IKDC subjective score & & & $55.7 \pm 2.9$ & 56.3 & $55.7-56.3$ & & & $56.8 \pm 5.3$ & 56.9 & $51.7-60.9$ & NS \\
\hline IKDC objective grade & & & & & & & & & & & NS \\
\hline B & 1 & 3.0 & & & & 1 & 3.3 & & & & \\
\hline C & 24 & 72.7 & & & & 22 & 73.3 & & & & \\
\hline $\mathrm{D}$ & 8 & 24.2 & & & & 7 & 23.3 & & & & \\
\hline
\end{tabular}

ACL: Anterior cruciate ligament; ALL: Anterolateral ligament; STA: Suture tape augmentation; SD: Standard deviation; Q1-Q3: First quarter-third quarter; SSD: Side-to-side differential; IKDC: International Knee Documentation Committee; NS: Not significant. 


\begin{tabular}{|c|c|c|c|c|c|c|c|c|c|c|c|}
\hline \multirow[b]{3}{*}{ Variables } & \multicolumn{10}{|c|}{$\begin{array}{c}\text { TABLE III } \\
\text { Comparison of postoperative outcomes among groups }\end{array}$} & \multirow[b]{3}{*}{$p$} \\
\hline & \multicolumn{5}{|c|}{ Group 1 (Isolated ACL) $(n=33)$} & \multicolumn{5}{|c|}{ Group $2(A C L+A L L ~ S T A)(n=30)$} & \\
\hline & $\mathrm{n}$ & $\%$ & Mean $\pm S D$ & Median & Q1-Q3 & $\mathrm{n}$ & $\%$ & Mean $\pm S D$ & Median & Q1-Q3 & \\
\hline SSD in anterior translation (mm) & & & $1.8 \pm 0.7$ & 2 & $1-4$ & & & $1.2 \pm 0.5$ & 1 & $0.5-3$ & NS \\
\hline Lachman test & & & & & & & & & & & NS \\
\hline 1 & 27 & 81.8 & & & & 28 & 93.3 & & & & \\
\hline II & 5 & 15.2 & & & & 2 & 6.6 & & & & \\
\hline III & 1 & 3 & & & & 0 & 0 & & & & \\
\hline & 0 & 0 & & & & 0 & 0 & & & & \\
\hline Pivot-shift test & & & & & & & & & & & NS \\
\hline 1 & 30 & 90.9 & & & & 30 & 100 & & & & \\
\hline II & 3 & 9.1 & & & & 0 & 0 & & & & \\
\hline III & 0 & 0 & & & & 0 & 0 & & & & \\
\hline Lysholm knee score & & & $87.8 \pm 4.4$ & 90 & $84-91$ & & & $89.2 \pm 4.5$ & 91 & $88.5-93$ & NS \\
\hline Cincinnati knee score & & & $89.2 \pm 4.2$ & 90 & $88-91$ & & & $90.5 \pm 3.7$ & 91 & $88-93$ & NS \\
\hline IKDC subjective score & & & $88.7 \pm 5.3$ & 88 & $85.1-95.4$ & & & $89.2 \pm 4.1$ & 88.5 & $86.2-92.2$ & NS \\
\hline IKDC objective grade & & & & & & & & & & & NS \\
\hline B & 29 & 87.9 & & & & 28 & 93.3 & & & & \\
\hline C & 4 & 12.1 & & & & 2 & 6.7 & & & & \\
\hline $\mathrm{D}$ & 0 & 0 & & & & 0 & 0 & & & & \\
\hline
\end{tabular}

not differ with respect to demographic characteristics and additional diagnoses or preoperative physical examination results (Tables I and II).

In Group 1, 9.1\% of the patients presented postoperative positive pivot shift $(90.9 \%$ Grade 0 and $9.1 \%$ Grade 1), whereas $0 \%$ of the patients in Group 2 presented postoperative positive pivot shift. The graft failure rate was $6.06 \%(\mathrm{n}=2)$ in Group 1 and $0 \%$ in Group 2 (Table III). Although the rotational instability, as evaluated by the pivotshift test, and failure rates were not statistically significant between the groups, Group 2 showed better rotational stability and a lower graft failure rate in the final evaluation than Group 1 ( $p=0.357$ and $\mathrm{p}=0.270$, respectively).

Regarding anterior stability (SSD), as evaluated by the KT-1000 arthrometer, Group 2 patients showed significantly better postoperative clinical results $(\mathrm{p}<0.006)$ (Table III). Although better results were obtained in Group 2, the clinical evaluation results for postoperative function did not differ significantly between groups $(\mathrm{p}=0.274$ for the Lysholm score, $\mathrm{p}=0.184$ for the Cincinnati score, $\mathrm{p}=0.803$ for the IKDC subjective score, and $\mathrm{p}=0.521$ for the IKDC objective grade) (Table III). The correlation coefficients used to assess interexaminer agreement regarding the KT-1000, Lachman test, and pivot-shift test were $0.989,0.881$, and 0.891 , respectively, and the levels of agreement were considered almost perfect according to the Landis and Koch classification.

Overall, when contralateral ACL injuries were excluded $(n=3), 95 \%$ of the remaining patients returned to sports at the latest follow-up. In addition, the tibial anchor was pulled out in the third month in one of the patients who had undergone STA, and the material was removed. No complications, such as infection, loss of ROM, arthrofibrosis or cyclops syndrome, were observed in either group. Two (6.6\%) patients in Group 2 had lateral discomfort in the first three weeks after surgery, and discomfort continued for up to one month, but none of these patients had rehabilitation disorders.

\section{DISCUSSION}

The main finding of this study is that compared with ACL reconstruction only, combined ACL reconstruction and ALL STA reduces the likelihood of ACL graft failure and improves anterior and rotation stability. However, we do not recommend performing ALL STA routinely for patients undergoing ACL reconstruction in view of the fact that the final results did not completely support our hypothesis; the only significant difference between the two groups was noted in the SSD results, and functional scores such as the Lysholm, Cincinnati, and IKDC scores presented similar results. ${ }^{[20]}$ 
Although a single-bundle ACL reconstruction can yield good to excellent functional outcomes, it is clear that in some patients, isolated ACL reconstruction may offer inadequate rotational control, and in these patients, return to play in pivoting sports can be delayed, and persistent rotational instability can lead to both cartilaginous and meniscal problems in the future. ${ }^{[21]}$ In the past, surgeons have, therefore, combined ACL reconstruction with lateral extra-articular tenodesis to overcome this problem, and many different techniques have been used. ${ }^{[22]}$ Most of these techniques were non-anatomical reconstructions, but most of them have been abandoned because improvements in arthroscopic ACL reconstruction have been made. ${ }^{[13,22]}$ To date, several techniques for anatomical ALL reconstruction have been described, but many of these techniques use a hamstring tendon (HT) autograft or allograft. ${ }^{[22]}$ With ALL STA, a tendon graft is not required; the native ligament is repaired in acute cases and retensioned in cases of a chronic ALL rupture. ${ }^{[13,12]}$ The risk of morbidity associated with harvesting a tendon graft is absent. ${ }^{[13]}$ The ALL STA technique is a simple, minimally invasive, and quick procedure that provides additional anterolateral rotational stability and is often performed together with ACL reconstruction. ${ }^{[13]}$ This technique encourages natural healing of the ALL, and in chronic cases, the ALL can regain the natural level of tension by tensioning the ALL. ${ }^{[13,12]}$ However, ALL STA has a higher cost, requires additional incision, and carries the risk of anchor pull out and lateral discomfort.

Smith et al. ${ }^{[23]}$ reported that, in patients who underwent combined ACL and ALL reconstruction, significant improvements were observed in objective and subjective outcomes at a mean follow-up of 32.4 months. Combined ACL and ALL reconstruction was found to be effective in improving subjective and objective outcomes according to Ibrahim et al. ${ }^{[6]}$ At a mean follow-up of 27 months, no statistically significant differences between the groups were reported with regard to the clinical examination findings. The authors reported that only anterior laxity was significantly better in the ALL reconstructed group, which supports the findings of previously published biomechanical studies about the ALL. ${ }^{[24-26]}$ Similarly, we found that only anterior laxity was significantly better in the group who underwent combined ALL STA and ACL reconstruction. Our general findings are very similar to their findings. However, five of the patients in the combined ALL and ACL reconstruction group in their study had a pivot shift of grade 1 or 2, and four had an IKDC score of $C$ at the final follow-up. On the other hand, none of the patients in the ALL STA group in our study had a pivot shift of grade 1 or 2 at the final follow-up, and none had an IKDC score of C.

Delaloye et al. ${ }^{[27]}$ demonstrated that compared with ACL reconstruction only, combined ACL and ALL reconstruction in a high-risk population is associated with significantly decreased graft rupture rates. Marcacci et al. ${ }^{[28]}$ reported a graft rupture rate of $2 \%$. In a very recent publication, Ferretti et al. ${ }^{[29]}$ compared isolated ACL reconstruction with combined ACL reconstruction and a modified Macintosh procedure and reported a significantly reduced graft failure rate with the combined procedure. In a prospective comparative study, Sonnery-Cottet et al. ${ }^{[30]}$ compared the outcomes of 502 patients who underwent primary ACL reconstruction with a bone-patellar tendonbone graft (B-PT-B), quadrupled HT (4HT) graft, and HT graft combined with ALL reconstruction (HT+ALL). At a mean follow-up of 38.4 months, the graft rupture rates were reported to be $10.77 \%$ for the 4 HT grafts, $16.77 \%$ for the B-PT-B grafts, and $4.13 \%$ for the HT+ALL grafts. The authors did not find significant differences between the groups with respect to the mean pre- and postoperative IKDC scores, SSD, or postoperative Lysholm and Tegner scores. Similarly, no differences were found between the pre- and postoperative scores in the present study. In our study, the graft rupture rate was $6.1 \%$ in Group 1 and $0 \%$ in Group 2 at the final follow-up, and the difference between the two groups was not statistically significant, perhaps because of the small sample size $(\mathrm{n}=63)$.

The main limitation of this study is its retrospective design. Also, ACL reconstructions with other types of grafts (allograft, patellar tendon) were not evaluated in this study, and our follow-up period was relatively short. Another limitation is that only FiberTape $^{\circledR}$ was used for ALL augmentation and was not compared with other ALL reconstruction techniques.

In conclusion, combined ALL STA and ACL reconstruction was found to be effective in improving subjective and objective outcomes. Nevertheless, these findings were not significantly superior to those of isolated ACL reconstruction with hamstring grafts, except for the SSD anterior laxity testing results. ALL STA is a relatively simple, quick, and tendon graft-free method; however, we do not recommend performing ALL STA routinely for patients undergoing ACL reconstruction. 


\section{Declaration of conflicting interests}

The authors declared no conflicts of interest with respect to the authorship and/or publication of this article.

\section{Funding}

The authors received no financial support for the research and/or authorship of this article.

\section{REFERENCES}

1. Atik OŞ. Surgical versus conservative treatment for torn anterior cruciate ligament. Jt Dis Relat Surg 2020;31:159-60.

2. Prodromos CC, Han Y, Rogowski J, Joyce B, Shi K. A metaanalysis of the incidence of anterior cruciate ligament tears as a function of gender, sport, and a knee injury-reduction regimen. Arthroscopy 2007;23:1320-5.e6.

3. Ajuied A, Wong F, Smith C, Norris M, Earnshaw P, Back $\mathrm{D}$, et al. Anterior cruciate ligament injury and radiologic progression of knee osteoarthritis: a systematic review and meta-analysis. Am J Sports Med 2014;42:2242-52.

4. Nebelung $\mathrm{W}$, Wuschech $\mathrm{H}$. Thirty-five years of follow-up of anterior cruciate ligament-deficient knees in high-level athletes. Arthroscopy 2005;21:696-702.

5. Samuelsson K, Andersson D, Karlsson J. Treatment of anterior cruciate ligament injuries with special reference to graft type and surgical technique: an assessment of randomized controlled trials. Arthroscopy 2009;25:1139-74.

6. Ibrahim SA, Shohdy EM, Marwan Y, Ramadan SA, Almisfer AK, Mohammad MW, et al. Anatomic reconstruction of the anterior cruciate ligament of the knee with or without reconstruction of the anterolateral ligament: A randomized clinical trial. Am J Sports Med 2017;45:1558-66.

7. Tashman S, Collon D, Anderson K, Kolowich P, Anderst W. Abnormal rotational knee motion during running after anterior cruciate ligament reconstruction. Am J Sports Med 2004;32:975-83.

8. Ristanis S, Giakas G, Papageorgiou CD, Moraiti T, Stergiou $\mathrm{N}$, Georgoulis AD. The effects of anterior cruciate ligament reconstruction on tibial rotation during pivoting after descending stairs. Knee Surg Sports Traumatol Arthrosc 2003;11:360-5.

9. Georgoulis AD, Ristanis S, Chouliaras V, Moraiti C, Stergiou N. Tibial rotation is not restored after ACL reconstruction with a hamstring graft. Clin Orthop Relat Res 2007;454:89-94.

10. Alp NB, Akdağ G, Kaleli T, Macunluoğlu AC, Uzunlulu N. Evaluation of patellar tendon with shear wave elastography after anterior cruciate ligament reconstruction using hamstring tendons. Jt Dis Relat Surg 2020;31:137-42.

11. Sofu H, Sahin V, Gürsu S, Yıldırım T, Issın A, Ordueri M. Use of quadriceps tendon versus hamstring tendon autograft for arthroscopic anterior cruciate ligament reconstruction: a comparative analysis of clinical results. Eklem Hastalik Cerrahisi 2013;24:139-43.

12. Monaco E, Mazza D, Redler A, Drogo P, Wolf MR, Ferretti A. Anterolateral ligament repair augmented with suture tape in acute anterior cruciate ligament reconstruction. Arthrosc Tech 2019;8:e369-73.

13. Heusdens CHW, Hopper GP, Dossche L, Mackay GM. Anterolateral Ligament Repair With Suture Tape Augmentation. Arthrosc Tech 2018;7:e1311-e4.

14. Inderhaug E, Stephen JM, Williams A, Amis AA. Anterolateral tenodesis or anterolateral ligament complex reconstruction: effect of flexion angle at graft fixation when combined with ACL reconstruction. Am J Sports Med 2017;45:3089-97.

15. Sonnery-Cottet B, Thaunat $M$, Freychet B, Pupim BH, Murphy CG, Claes S. Outcome of a combined anterior cruciate ligament and anterolateral ligament reconstruction technique with a minimum 2-year follow-up. Am J Sports Med 2015;43:1598-605.

16. Getgood A, Brown C, Lording T, Amis A, Claes S, Geeslin A, et al. The anterolateral complex of the knee: results from the International ALC Consensus Group Meeting. Knee Surg Sports Traumatol Arthrosc 2019;27:166-76.

17. Dabis J, Wilson A. Repair and augmentation with internal brace in the multiligament injured knee. Clin Sports Med 2019;38:275-83.

18. Sonnery-Cottet B, Barbosa NC, Tuteja S, Daggett M, Kajetanek C, Thaunat M. Minimally invasive anterolateral ligament reconstruction in the setting of anterior cruciate ligament injury. Arthrosc Tech 2016;5:e211-5.

19. Helito $\mathrm{CP}$, Sobrado MF, Giglio PN, Bonadio MB, Pécora JR, Camanho GL, et al. Combined reconstruction of the anterolateral ligament in patients with anterior cruciate ligament injury and ligamentous hyperlaxity leads to better clinical stability and a lower failure rate than isolated anterior cruciate ligament reconstruction. Arthroscopy 2019;35:2648-54.

20. Atik OŞ. Is there something new and interesting in my article? Eklem Hastalik Cerrahisi 2019;30:69.

21. Chouliaras V, Ristanis S, Moraiti C, Stergiou N, Georgoulis AD. Effectiveness of reconstruction of the anterior cruciate ligament with quadrupled hamstrings and bone-patellar tendon-bone autografts: an in vivo study comparing tibial internal-external rotation. Am J Sports Med 2007;35:189-96.

22. Roessler PP, Schüttler KF, Heyse TJ, Wirtz DC, Efe T. The anterolateral ligament (ALL) and its role in rotational extra-articular stability of the knee joint: a review of anatomy and surgical concepts. Arch Orthop Trauma Surg 2016;136:305-13.

23. Smith JO, Yasen SK, Lord B, Wilson AJ. Combined anterolateral ligament and anatomic anterior cruciate ligament reconstruction of the knee. Knee Surg Sports Traumatol Arthrosc 2015;23:3151-6.

24. Pomajzl R, Maerz T, Shams C, Guettler J, Bicos J. A review of the anterolateral ligament of the knee: current knowledge regarding its incidence, anatomy, biomechanics, and surgical dissection. Arthroscopy 2015;31:583-91.

25. Parsons EM, Gee AO, Spiekerman C, Cavanagh PR. The biomechanical function of the anterolateral ligament of the knee. Am J Sports Med 2015;43:669-74.

26. Kennedy MI, Claes S, Fuso FA, Williams BT, Goldsmith MT, Turnbull TL, et al. The anterolateral ligament: An anatomic, radiographic, and biomechanical analysis. Am J Sports Med 2015;43:1606-15.

27. Delaloye JR, Murar J, Gonzalez M, Amaral T, Kakatkar V, Sonnery-Cottet B. Clinical outcomes after combined anterior cruciate ligament and anterolateral ligament reconstruction. Tech Orthop 2018;33:225-31.

28. Marcacci M, Zaffagnini S, Giordano G, Iacono F, Presti ML. Anterior cruciate ligament reconstruction associated with extra-articular tenodesis: A prospective clinical and radiographic evaluation with 10- to 13-year follow-up. Am J Sports Med 2009;37:707-14.

29. Ferretti A, Monaco E, Ponzo A, Basiglini L, Iorio R, Caperna $\mathrm{L}$, et al. Combined Intra-articular and Extra-articular Reconstruction in Anterior Cruciate Ligament-Deficient Knee: 25 Years Later. Arthroscopy 2016;32:2039-47.

30. Sonnery-Cottet B, Saithna A, Cavalier M, Kajetanek C, Temponi EF, Daggett $M$, et al. Anterolateral Ligament Reconstruction Is Associated With Significantly Reduced ACL Graft Rupture Rates at a Minimum Follow-up of 2 Years: A Prospective Comparative Study of 502 Patients From the SANTI Study Group. Am J Sports Med 2017;45:1547-57. 